regulates cell adhesion ${ }^{19}$ provide further experimental evidence that the pieces in this puzzle are finally beginning to come together.

A K NIGAM

Research fellow

Department of Surgery,

Rayne Institute,

University College London,

London WC1E 6JJ

Department of Histopathology,

M PIGNATELLI Senior lecturer

Royal Postgraduate Medical School,

London W12 0NN

1 Paget S. The distribution of secondary growths in cancer of the breast. Lancet 1889;i:571-3.

2 Coman DR. Decreased mutual adhesiveness, property of cells from squamous cell carcinomas. Cancer Res 1944;4:625-9.

3 Hynes RO. Integrins: versatility, modulation, and signalling in cell adhesion. Cell 1992;69:11-25.

4 Albelda SM, Buck CA. Integrins and other cell adhesion molecules. FASEB f 1990;4:2868-80.

5 Weinberg RA. Tumour suppressor genes. Science 1991;254:1138-46.
6 Liotta LA, Stetler-Stevenson WG. Tumour invasion and metastasis: an imbalance of positive and negative regulation. Cancer Res 1991;51:5054-9s.

7 Aznavoorian S, Stracke ML, Krutzsch H, Schiffman E, Liotta LA. Signal transduction for chemotaxis and haptotaxis by matrix molecules in tumour cells. F Cell Biol 1990;110:1427-38.

8 Ruoslahti E, Giancotti FG. Integrins and tumour cell dissemination. Cancer Cells 1989;1:119-26.

9 Shiozaki $\mathrm{H}$, Tahara $\mathrm{H}$, Oka $\mathrm{H}$, Miyata $M$, Kobayashi $\mathrm{K}$, Tamura $\mathrm{S}$, et al. Expression of izan $\mathrm{H}$, Tahara $\mathrm{H}$, Oka $\mathrm{H}$, Miyata M, Kobayashi K, Tamura S, et al. Expression of

immunoreactive E-cadherin adhesion molecules in human cancers. Am $\mathcal{F}$ Pathol 1991;139:17-23. poorly differentiated colorectal adenocarcinomas. Br Y Cancer 1990;61:636

11 Nigam AK, Savage FJ, Boulos PB, Stamp GWH, Liu D, Pignatelli M. Loss of cell-cell and cell-matrix adhesion molecules in colorectal cancer. Br $f$ Cancer (in press).

12 Harris CC. Human tissues and cells in carcinogenesis research. Cancer Res 1987;47:1-10.

13 Spremulli EN, Dexter DL. Polar solents: a novel class of antineoplastic agents. $\mathcal{J}$ Clin Oncol 1984;2:227-41

14 Pignatelli M, Liu D, Nasim MM, Stamp GWH, Hirano S, Takeichi M. Morphoregulatory activities of E-cadherin and beta-1 integrins in colorectal tumour cells. $\mathrm{Br} \mathcal{f}$ Cancer 1992;66: 629-34

15 Vleminckx K, Vakaet L Jr, Mareel M, Fiers W, Van Roy F. Genetic manipulation of E-cadherin expression by epithelial tumour cells reveals an invasion suppressor role. Cell 1991;66:107-19.

16 Seftor REB, Seftor EA, Gehlsen KR, Stetler-Stevenson WG, Brown PD, Ruoslahti E, et al. Role of the avB3 integrin in human melanoma cell invasion. Proc Natl Acad Sci USA 1992;89:1557-61.

17 Pignatelli $M$, Bodmer WF. Integrin receptor mediated differentiation and growth inhibition are enhanced by transforming growth factor- $\beta$ in colorectal tumour cells grown in collagen gel. Int $\mathcal{J}$ Cancer 1989;44:518-23.

18 Rougon G, Durbec P, Figarella-Branger D. Adhesion molecules in cancer. Cancer $\mathcal{F}$ 1992;5:137-41.

19 Pullman WE, Bodmer WF. Cloning and characterisation of a gene that regulates cell adhesion. Nature 1992;356:529-32.

\title{
Searching for gastrinomas
}

\section{Visceral angiography is improving detection}

The three main causes of peptic ulceration are infection with Helicobacter pylori, ingestion of non-steroidal antiinflammatory drugs, and the gastrinoma (Zollinger-Ellison) syndrome. Effective treatment now exists for the first two conditions: antibiotics, especially in the presence of effective acid inhibition, cure most ulcers related to $H$ pylori infection. Coadministration of antisecretory agents and misoprostol may prevent damage induced by non-steroidal anti-inflammatory drugs.

Patients with the gastrinoma syndrome, once the syndrome has been diagnosed, can be treated with high dose proton pump inhibitors such as omeprazole. These patients remain at risk, however, of considerable morbidity and mortality from gastrinoma metastases. Thus it is important to identify the one in 1000 patients with peptic ulceration who has a gastrinoma and to remove it.

What increases the likelihood that a patient will have a gastrinoma? Such patients have a history of severe ulcer disease refractory to medical treatment, often occurring in atypical sites such as the oesophagus and jejunum. Complications, such as stricture or haemorrhage, occur frequently, and patients may have acid driven severe watery diarrhoea, sometimes antedating the ulceration. To diagnose the condition a raised gastrin concentration should be found in a plasma sample taken from the fasting patient. Treatment with omeprazole must be stopped two weeks, and $\mathrm{H}_{2}$ blockers three days, before sampling. The commonest confounding cause of a raised gastrin concentration is relative hypochlorhydria, even in patients with active peptic ulcer disease. Chronic renal failure or hypercalcaemia may cause hypergastrinaemia in patients with common peptic ulcer disease.

To distinguish between these conditions basal gastric acid output must be measured. Only in the gastrinoma syndrome is a high gastrin concentration associated with an increased acid output. A basal output of 10-15 mmol of hydrochloric acid per hour is suspicious of the diagnosis and an output greater than $15 \mathrm{mmol} /$ hour is characteristic. Measuring acid output after stimulation with pentagastrin does not improve diagnostic accuracy.

The intravenous secretin test has been advocated as an alternative to measuring gastric acid output. This test relies on the fact that the autonomous gastrinoma increases gastrin secretion in response to secretin. In patients with ulcers but without gastrinomas a balance exists between stimulation of the gastrin secreting G-cells by secretin and inhibition by local factors, such as somatostatin, so that gastrin concentrations rise to a much lesser extent, if at all. ${ }^{12}$ The best criteria for diagnosing the gastrinoma syndrome with the secretin test are based on the absolute rise in gastrin concentration and so must be standardised for individual assay laboratories.

Regrettably, a significant rise in plasma gastrin concentration has also been found in some patients with hypergastrinaemia related to achlorhydria ${ }^{3}$ and also in patients with peptic ulcer disease but without a gastrinoma. ${ }^{4}$ Adjusting the criteria to minimise the rate of false positive results reduces the sensitivity of the secretin test to about $80 \%$. Thus it should be reserved for those patients who have equivocally raised acid output or plasma gastrin concentration or who are unable to stop taking omeprazole because of rapidly recurring severe ulceration.

Once a gastrinoma has been diagnosed it must be localised. Nine out of 10 sporadic gastrinomas occur in the gastrinoma triangle, bounded by the third part of the duodenum, the neck of the pancreas, and the porta hepatis; up to $40 \%$ of these are in the duodenum. ${ }^{78}$ Pancreatic gastrinomas have already metastasised to the liver in over half of cases, but duodenal gastrinomas have been reported to be clinically less malignant, with only $10 \%$ associated with hepatic metastases. Yet metastasis to local lymph node occurs in as many as $70 \%$ of duodenal gastrinomas less than $0.5 \mathrm{~cm}$ in diameter (microgastrinomas). All gastrinomas must therefore be regarded as possibly malignant, and curative surgery should be performed whenever possible. ${ }^{67}$

Some $60 \%$ of gastrinomas are greater than $1 \mathrm{~cm}$ in diameter, often with associated hepatic metastases, and these can almost always be identified with transabdominal ultrasonography and abdominal computed tomography. Magnetic resonance imaging, with present technology, does not seem to improve the sensitivity of these techniques. ${ }^{8}$ The remaining $40 \%$ of gastrinomas represent the major clinical problem as these tumours are likely to be amenable to curative resection and yet their localisation by conventional imaging is poor.

Highly selective angiography improves localisation, with angiographic detection rates from specialist referral centres 
varying from $38 \%$ to $70 \%$. ${ }^{10}$ Surgeons fail to localise between a third and a half of non-metastatic gastrinomas intraoperatively, so techniques to enhance preoperative localisation are clearly needed. ${ }^{67}$ Transhepatic portal venous sampling has a sensitivity of only about $50 \%$ for microgastrinomas. This procedure can only regionalise, not localise, tumours and so the surgeon gains little useful information. ${ }^{11}$

Recently, selective arterial injection of secretin with angiography has been reported to localise $77-100 \%$ of gastrinomas, detecting tumours as small as $1 \mathrm{~mm} .{ }^{69}$ This new procedure relies on the exaggerated rise in gastrin concentration in the hepatic vein after injection of secretin into the artery supplying the tumour. Its advantages are high resolution and low morbidity as it is performed during conventional angiography. The local injection of secretin can show that angiographic abnormalities are functioning gastrinomas and can detect hepatic micrometastases when secretin is injected into the hepatic artery. Additionally, an intraoperative intravenous secretin test, using a rapid turnaround gastrin assay, can confirm that the tumour has been successfully cleared. ${ }^{6}$ Although experienced operators have reported similar localisation rates for endoscopic ultrasonography, ${ }^{1213}$ there are no reports that tumours smaller than $0.5 \mathrm{~cm}$ in diameter have been localised ultrasonographically, and the sensitivity falls the further the lesion is from the probe.

There is conflicting evidence concerning the impact of new imaging techniques on curative resection. Howard and colleagues report an improvement in cure rate from $27 \%$ to $87 \%$ in recent years, but the mean follow up of the recently operated group was only nine months. ${ }^{14}$ In contrast, Norton and colleagues found that the long term cure rate remains about $30 \%$ despite a disease free rate at three to six months' follow up of about $60 \% .^{15}$

Nearly a third of patients with a gastrinoma will have multiple endocrine neoplasia type 1 . The disease is usually multicentric, with tumours throughout the duodenum and pancreatic head, and an increased incidence of duodenal microgastrinomas. The tumours are apparently more benign than sporadic gastrinomas, although this may reflect earlier diagnosis. In patients with concurrent hyperparathyroidism the clinical and biochemical features of the gastrinoma syndrome are exacerbated, and parathyroidectomy should therefore be performed.

The subsequent surgical management of gastrinomas associated with multiple endocrine neoplasia type I is controversial. The multifocal nature of the disease, even without metastases, makes curative resection unlikely, and management is usually enucleation of gross, potentially metastatic lesions and control of symptoms with omeprazole. It has been suggested, however, that there is a subgroup of patients who have localised secretion of gastrin and thus may be cured. ${ }^{16}$ Selective arterial injection of secretin will allow identification of this subgroup.

P J HAMMOND MRC training fellow S R BLOOM

Department of Medicine, Professor of endocrinology

Hammersmith Hospital,

London W12 0HS

1 Hattori $Y$, Imamura $M$, Tobe $T$. Gastrin release from antral $G$ cells stimulated with secretin. Am $\mathcal{J}$ Gastroenterol 1992;87:195-200.

2 Chiba T, Yamatani T, Yamaguchi A, Morishita T, Nakamura A, Kadowaki S, et al. Mechanism for increase of gastrin release by secretin in Zollinger-Ellison syndrome. Gastroenterology 1989;96: 1439-44.

3 Feldman M, Schiller LR, Walsh JH, Fordtran JS, Richardson CT. Positive intravenous secretin test in patients with achlorhydria-related hypergastrinaemia. Gastroenterology 1987;93:59-62.

4 Stage JG, Stadil F, Rehfled JF, Kahrenkrug J, Schaffelitzky de Muckadell OB. Secretin and the Zollinger-Ellison syndrome: reliability of secretin tests and pathogenetic role of secretin. Scand $\mathcal{J}$ Gollinger-Ellison syndrome:

5 Primrose JN, Ratcliffe JG, Joffe SN. Differences between peptic ulcer and control patients on the basis of the response to secretin. Digestion 1985;32:249-54.

6 Imamura $M$, Kanda $M$, Takahashi K, Shimada Y, Miyahara T, Wagata T, et al. Clinicopathological characteristics of duodenal microgastrinomas. World f Surg 1992;16:703-10.

7 Thom AK, Norton JA, Axiotis CA, Jensen RT. Location, incidence, and malignant potential of duodenal gastrinomas. Surgery 1991;110:1086-91.

8 Frucht H, Doppman J, Norton JA, Miller DL, Dwyer AJ, Frank JA, et al. MR imaging of gastrinomas: comparison with computed tomography, angiography and ultrasound. Radiology 1989;171:713-8.

9 Doppman JL, Miller DL, Chang R, Maton PN, London JF, Gardner JD, et al. Gastrinomas: localisation by means of selective intra-arterial injection of secretin. Radiology 1990;174:25-9.

10 Maton PN, Miller DL, Doppman JL, Collen MJ, Norton JA, Vinayek R, et al. Role of selective angiography in the management of patients with Zollinger-Ellison syndrome. Gastroenterology 1987;92:913-8.

11 Vinik AI, Moattari AR, Cho K, Thompson N. Transhepatic portal vein catheterisation for localisation of sporadic and MEN gastrinomas: a ten-year experience. Surgery 1990;107:246-55.

Rosch T, Lightdale CJ, Botet JF, Boyce GA, Sivak MV Jr, Yasuda K, et al. Localisation of pancreatic endocrine tumours by endoscopic ultrasonography. N Engl f Med 1992;326:1721-6.

13 Palazzo L, Roseau G, Salmeron M. Endoscopic ultrasonography in the preoperative localisation of pancreatic endocrine tumours. Endoscopy 1992;24:350-3.

14 Howard TJ, Zinner MJ, Stabile BE, Passaro E Jr. Gastrinoma excision for cure. A prospective analysis. Ann Surg 1990;211:9-14.

15 Norton JA, Doppman JL, Jensen RT. Curative resection in Zollinger-Ellison syndrome. Results of a 10-year prospective study. Ann Surg 1992;215:8-18.

6 Thompson NW, Bondeson AG, Bondeson L, Vinik A. The surgical treatment of gastrinoma in MEN 1 syndrome patients. Surgery 1989;106:1081-5.

\section{Reviewing the NHS review}

\section{More substantial changes on the way}

The future direction of the NHS reforms is currently under scrutiny by a review team established by Virginia Bottomley. The decision to appoint the team was announced in February at a conference on managing the market. At that time it was seen primarily as a way of resolving the future of the intermediate tier of NHS management-the term used to describe the 14 regional health authorities and six outposts of the management executive.

In the event, much wider terms of reference have been established.' These centre on an analysis of what needs to be done to ensure that the NHS reforms are fully effected. General practice fundholders and NHS trusts have an assured future, but all other aspects of the structure of the NHS are being scrutinised. What was originally perceived as a technical exercise of interest mainly to NHS insiders has thus become a fundamental examination of the reforms as a whole.

The reasons for this are not hard to find. The most important is the involvement of the prime minister's office, spurred on by a concern within the government to ensure that Mrs Bottomley remains faithful to the original purpose of the reforms. At one level this is manifested in the desire to ensure that NHS trusts are not enmeshed in unnecessary bureaucratic controls at the intermediate tier. More fundamentally, it stems from a policy of cutting back on inappropriate central and regional controls to enable the market to come into play more fully. At the same time the review provides an opportunity to tidy up some of the loose ends that have emerged, such as the overlapping responsibilities of district health authorities and family health services authorities and the relation between these authorities and general practice fundholders.

The membership of the review team gives some clues as to the likely outcome of its work. Of particular significance is the appointment of Kate Jenkins to lead the review. Ms Jenkins is 